\title{
Differences in physical fitness after an 8-week preseason training among elite football players aged $17-19$ years
}

\author{
Hojun Lee', Chang-Hwa Joo ${ }^{2, *}$ \\ 'Department of Human Movement Science, Seoul Women's University, Seoul, Korea \\ ${ }^{2}$ Department of Sport Science, Kangwon National University, Chuncheon, Korea
}

There may be an optimal period of time to maximize the improvement of physical fitness during adolescence. The aim of this study was to examine the magnitude of changes in physical fitness after 8 weeks of preseason training according to chronological ages after the age at peak high velocity. Thirty male young football players from an elite football team (U-16, $n=10 ; U-17, n=10 ; U-18, n=10)$ participated in the study. The players completed an 8-week general preseason football training and participated in the pre- and posttests to measure physical fitness. The 8-week preseason training improved the power of all young players $(P<0.05)$. The $20-\mathrm{m}$ sprint performance was improved by training in $\mathrm{U}-16$ and $\mathrm{U}-18(P<0.05)$, but no changes were found in the $\mathrm{U}-17$ group $(P>0.05)$. Significant differences were found in the arrowhead left in
U-16 and U-18 $(P<0.05)$ after training; however, no difference was observed in $U-17(P>0.05)$. Coordination was enhanced further in U-16 and $\mathrm{U}-17(P<0.05)$ compared with that in U-18 $(P>0.05)$. The performance of repeated sprints and $Y_{0}-Y_{0}$ intermittent recovery test level 1 ( $Y_{0}-Y_{0}$ IR1) were similar between pre- and posttraining in all age groups $(P>0.05)$. Collectively, the results emphasized the importance of systematic and scientific training methods to improve the fitness levels of young football players in the preseason training period. Moreover, training to improve coordination in young football players is effective at younger ages.

Keywords: Football player, Preseason training, Physical fitness

\section{INTRODUCTION}

A high fitness level is demanded among football players to perform a 90-min football game successfully. Many training methods have been developed to increase physical fitness among football players. However, these training methods vary according to the aim of training, that is, to develop physical fitness components such as power, endurance, and speed endurance. Based on the periodization theory, training phases for football players for a year are divided into four periods: preseason, early competition, late competition, and transition phases (Mara et al., 2015). Preseason training mainly aims to develop fitness without injury in preparation for the impending early and late competition seasons. In fact, training loads for elite football players during preseason are higher than those during in-season (Jeong et al., 2011).

The level of physical fitness is closely associated with biological maturation of elite football players during adolescence. The peak height velocity is a well-known important criterion to assess the magnitude of physical fitness development and decline in motor coordination performance. The age and magnitude of peak height velocity vary with activity level during adolescence. Bell (1993) estimated that the peak height velocity and age at peak height velocity were $8.5 \pm 1.2 \mathrm{~cm}(14.1 \pm 0.8$ years $)$ and $9.5 \pm 1.5 \mathrm{~cm}(14.2 \pm$ 0.9 years) per year in sedentary and active boys, respectively. The estimated average age at peak height velocity for young football players was $13.8 \pm 0.8$ years $(9.7 \pm 1.5 \mathrm{~cm}$ per year) (Philippaerts et al., 2006). The aerobic and anaerobic performances of football players showed peak development at peak height velocity, and the performances continued to improve after peak height velocity (Philippaerts et al., 2006).

Several studies have examined the differences in the levels of physical fitness according to age after peak height velocity during
${ }^{*}$ Corresponding author: Chang-Hwa Joo (D) https://orcid.org/0000-0002-7429-3104 Department of Sport Science, Kangwon National University, 1 Kangwondaehak-gil, Chuncheon 24341, Korea

E-mail: phd.football@gmail.com

Received: August 7, 2020 / Accepted: September 3, 2020
This is an Open Access article distributed under the terms of the Creative Commons Attribution Non-Commercial License (https://creativecommons.org/licenses/by-nc/4.0/) which permits unrestricted non-commercial use, distribution, and reproduction in any medium, provided the original work is properly cited. 
adolescence (Buchheit et al., 2013) and the influence of football training on physical fitness after the chronological age at peak height velocity during adolescence (Impellizzeri et al., 2006; McMillan et al., 2005). The findings from such studies indicate that physical fitness level varies among chronological ages after peak height velocity and that fitness was improved after several weeks of training at similar age groups. A relevant question is whether the magnitude of improvements in physical fitness after prolonged period of football-specific training differs among young football players. However, limited work has been undertaken to determine the differences in physiological adaptations after several weeks of training according to ages after the peak high velocity.

Young football players in a team perform the fitness training in a similar way regardless of their characteristics, including age and anthropometric and genetic factors, because of the lack of expertise and scientific information. However, to maximize training adaptations for young football players after the age at peak high velocity during adolescence, organized training in consideration of the trainability of physical performance according to ages is necessary. For example, the more trainable period for anaerobic capacity during high-intensity exercise is in the late adolescence than in preadolescence (Philippaerts et al., 2006). To determine the precise trainable period according to different physical fitness components during adolescence after the age at peak high velocity, the study providing details regarding the effect of football-specific training for several weeks in different ages on physical adaptations during the late adolescence is needed. Therefore, this study aimed to examine the magnitude of changes in physical fitness after 8 weeks of preseason training according to chronological ages after the age at peak high velocity.

\section{MATERIALS AND METHODS}

\section{Participants}

Thirty male young football players from an elite football team (U-16, $\mathrm{n}=10 ; \mathrm{U}-17, \mathrm{n}=10 ; \mathrm{U}-18, \mathrm{n}=10$ ) participated in the study.
The subjects who completed and regularly participated in all training sessions are included in the study. Goalkeepers were excluded from this study. The subjects' height, body mass, and body mass index are shown in Table 1. Before testing, all participants gave written informed consent to participate after details and procedures of the study had been fully explained. The study was conducted according to the Declaration of Helsinki and all of the experimental protocols and related procedures were approved by the ethical committee of Kangwon National University (KWNUIRB-201904-008-003). All subjects were provided daily food developed by a nutritionist to ensure adequate fluid and nutrient intake during the study.

\section{Experimental design}

To determine whether the preseason training for 8 weeks has different effects on physical fitness components according to ages, young elite football players participated in the pre- and posttests to measure their performances. The players completed the tests on an artificial field-turf pitch. The tests were conducted for 2 days: in day 1,30-m sprint test, arrowhead agility test, coordination test, and Yo-Yo intermittent recovery level 1 (Yo-Yo IR1) test were conducted; and in day 2, repeated sprint test was carried out. A 30-m sprint test, arrowhead agility test, and coordination test were performed in the morning. The Yo-Yo IR1 test was conducted in the evening with $5 \mathrm{hr}$ of recovery after lunch. After an approximately 20-min warm-up period consisting of jogging and static and dynamic stretching, the players performed the tests. For full recovery, 10-min rests were given between tests. During resting time, the players were allowed to drink water.

Pretest was conducted after 2 weeks of preseason training; thereafter, the players performed 8 weeks of preseason training. During the preseason training period, the players had 9-11 football training sessions per week. The training sessions were conducted in the morning ( 60 min) and evening ( 120 min). The morning sessions were basically organized to develop physical fitness. The conditioning priority of physical fitness training according to training

Table 1. Characteristics of the youth players

\begin{tabular}{|c|c|c|c|c|c|c|}
\hline \multirow{2}{*}{ Characteristic } & \multicolumn{2}{|c|}{ U-16 $(16.2 \pm 0.2 y r)$} & \multicolumn{2}{|c|}{ U-17 (17.3 $\pm 0.1 \mathrm{yr})$} & \multicolumn{2}{|c|}{ U-18 (18.5 $\pm 0.2 y r)$} \\
\hline & Pre & Post & Pre & Post & Pre & Post \\
\hline Height (cm) & $172.0 \pm 7.5$ & $172.7 \pm 6.7$ & $176.7 \pm 6.9$ & $176.9 \pm 6.8$ & $178.4 \pm 8.2$ & $178.8 \pm 8.0$ \\
\hline Body mass $(\mathrm{kg})$ & $63.8 \pm 8.7$ & $64.0 \pm 8.4$ & $67.2 \pm 5.1$ & $67.3 \pm 4.9$ & $65.0 \pm 9.6$ & $65.3 \pm 9.3$ \\
\hline $\mathrm{BMI}\left(\mathrm{kg} / \mathrm{m}^{2}\right)$ & $21.5 \pm 1.5$ & $21.4 \pm 1.5$ & $21.5 \pm 1.3$ & $21.5 \pm 1.3$ & $20.5 \pm 2.7$ & $20.5 \pm 2.7$ \\
\hline
\end{tabular}

BMl, body mass index.

The data are presented as the mean \pm standard deviation. 
weeks was endurance capacity for the first 3 weeks (1st to 2 nd week for aerobic development sessions; 3 rd week for aerobic maintenance sessions), running speed variation sessions for 1 week (4th week), speed endurance for 3 weeks ( 5 th week for speed endurance maintenance sessions; 6th to 7 th week for speed endurance production sessions), and speed for the last 1 week (8th week). The evening sessions generally consisted of technical and tactical training and simulated competition ( $\sim 4 \mathrm{hr}$ after the morning session). After the 8 -week preseason training period, the players participated in the posttest for 2 days. The tests were performed approximately at the same time of the day and order, with operators unaware of the players' allocation to the different ages. The values were compared with those of the pretest to determine the differences in training effects according to ages.

\section{0-m sprint test}

The sprint tests which consisted of 2 maximal sprints of $30 \mathrm{~m}$ with 2-min rest between each sprint were conducted. The sprint times at 5, 10, 20, and $30 \mathrm{~m}$ were recorded using the photocell gates (Microgate, Bolzano, Itaia). The participants started to run $50 \mathrm{~cm}$ before the photocell gate recordings. The fastest times at the distances were recorded for data analysis (Joo, 2016).

\section{Arrowhead agility test}

The arrowhead agility tests consisted of 4 sprints (2 right, 2 left), with 2-min rest between each sprint (Noon et al., 2015). Each subject started $50 \mathrm{~cm}$ behind the start line and sprinted $10 \mathrm{~m}$ forward to a cone. From the cone, the subjects turned at a right angle to a cone being apart from $5 \mathrm{~m}$ before turning to a cone $15 \mathrm{~m}$ straight from the start line. They turned again from the cone to accelerate in a straight line for $15 \mathrm{~m}$ over the initial start line to complete the run. The fastest times were recorded for data analysis. Timing gates were used to accurately assess the time to completion.

\section{Vertical jump}

The players completed vertical jump twice on a pad with sort of compatible height measurer attached (Nike SPARQ, Beaverton, OT, USA) (Burris et al., 2020). Each player strated standing with both feet on the pad and performed jump with full arm swing to initiate the jump. The highest score was recorded for data analysis.

\section{Coordination test}

The subjects completed the 44-m slalom dribble twice with 5-min rest between each test (Joo, 2016). Each subject started $50 \mathrm{~cm}$ behind the start line and dribbled a football ball around
14 cones. If the subject touches the cones, 2 sec were added to the recording time. The fastest times were recorded for data analysis. Timing gates were used to accurately assess the time to completion.

\section{Repeated sprint test}

The repeated sprint test consisted of seven maximal 34.2-m sprints, interspersed by $25 \mathrm{sec}$ of active recovery (40-m jogging distance) (Abrantes et al., 2004). Recovery was timed so that the subjects returned to the start line between the 23rd and 24th second. Additionally, verbal feedback was given at 5, 10, 15, and 20 sec of the recovery. Performance was measured as the total sprint time in seconds.

\section{Yo-Yo intermittent recovery test}

The Yo-Yo IR1 test was performed on an artificial turf. The YoYo IR1 test consists of $2 \times 20-\mathrm{m}$ shuttle runs at increasing speeds, controlled by audio signals from a compact disk. Between each bout of running, the subjects completed 10 sec of active recovery, consisting of $2 \times 5-\mathrm{m}$ jogging (Bangsbo et al., 2008). The test was terminated when the subjects failed twice to reach the start line on time and the distance $(\mathrm{m})$ covered at the end point was recorded (Thomassen et al., 2010).

\section{Statistical analyses}

Statistical analyses were carried out using IBM SPSS Statistics ver. 23.0 (IBM Co., Armonk, NY, USA). Data are presented as mean \pm standard deviation. A two-factor (condition $\times$ time) within-participants general linear model was undertaken to determine any age differences between the pre- and posttraining. Data at the posttraining time points were compared with the pretraining time point using paired $t$-test. The alpha level for evaluation of statistical significance was set at $P<0.05$.

\section{RESULTS}

The 8-week preseason training improved the power of all young players (U-16, U-17, U-18, $P<0.05$ ) (Fig. 1). Rates of changes in jump performance were $4.5 \% \pm 3.0 \%$ (U-16), $4.3 \% \pm 3.1 \%$ (U-17), and $4.0 \% \pm 2.5 \%$ (U-18).

The 10-m sprint performance (U-16, 0.9\% $\pm 4.7 \%$; U-17, $1.0 \% \pm 2.7 \%$; U-18, $1.1 \% \pm 2.5 \%)$ showed no change after training in all age groups (Fig. $2 \mathrm{~A})(P>0.05)$. The 20 -m sprint performance was improved by training in U-16 $(2.8 \% \pm 3.2 \%)$ and U-18 $(1.7 \% \pm 1.4 \%)$ (Fig. 2B) $(P<0.05)$, but no changes were 


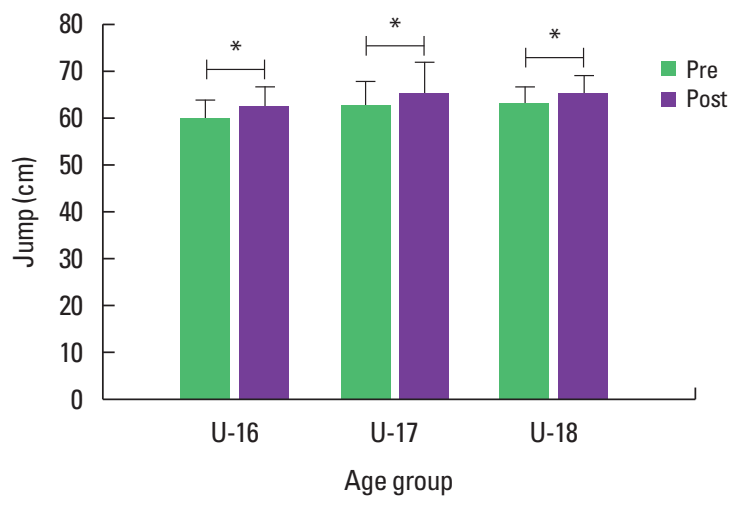

Fig. 1. Jump in the age groups before and after 8-week preseason training $(n=10$, mean \pm standard deviation). There were significant changes in the variable for U-16, U-17, and U-18. *Significant difference between pre- and posttraining $(P<0.05)$.

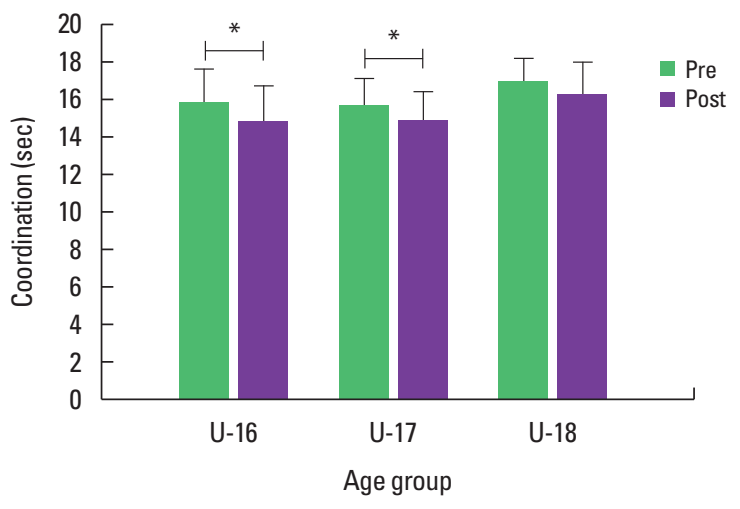

Fig. 4. Coordination in the age groups before and after 8-week preseason training ( $n=10$, mean \pm standard deviation). There were significant changes in the variable for $\mathrm{U}-16$ and $\mathrm{U}-17$. *Significant difference between pre- and posttraining $(P<0.05)$.
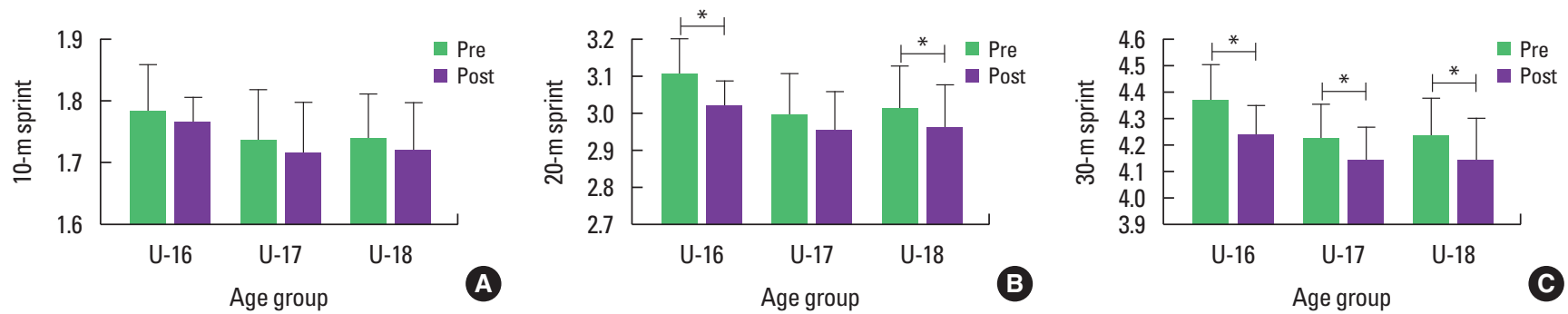

Fig. 2. Sprints (A, $10 \mathrm{~m} ; \mathrm{B}, 20 \mathrm{~m} ; \mathrm{C}, 30 \mathrm{~m})$ in the age groups before and after 8-week preseason training $(\mathrm{n}=10$, mean \pm standard deviation). There were significant changes in $20 \mathrm{~m}$ for U-16 and U-18 and $30 \mathrm{~m}$ for U-16, U-17, and U-18. * Significant difference between pre- and posttraining $(P<0.05)$.
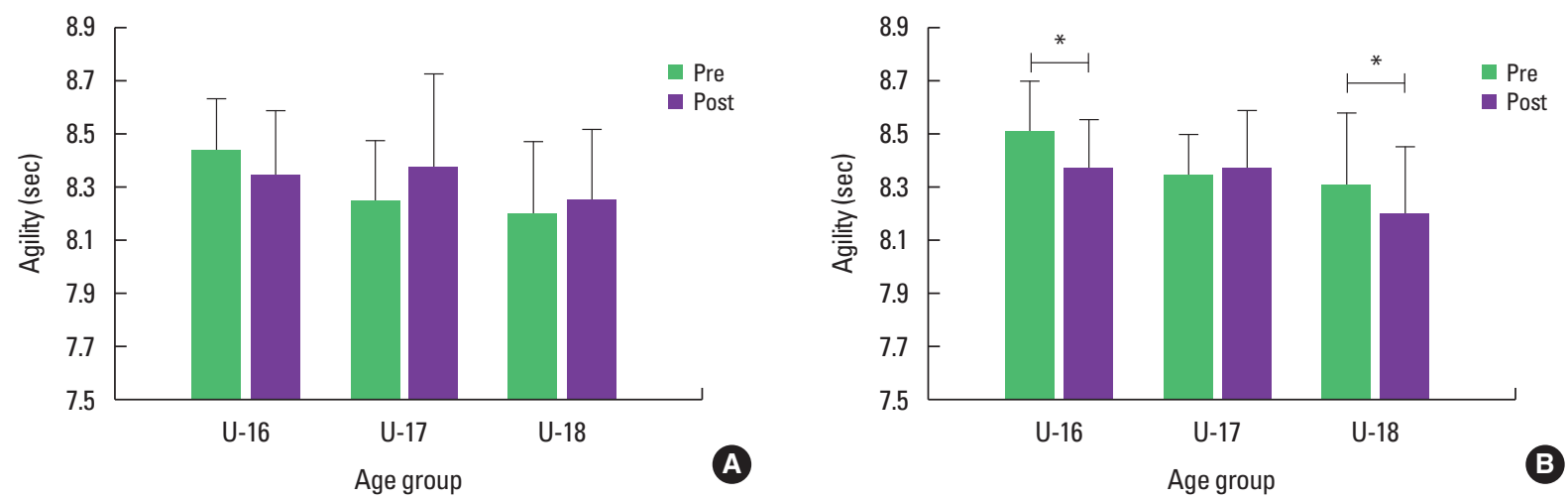

Fig. 3. Arrowhead agility (A, right; $B$, left) in the age groups before and after 8-week preseason training $(n=10$, mean \pm standard deviation). There were significant changes in the left for U-16 and U-18. * Significant difference between pre- and posttraining $(P<0.05)$.

found in the U-17 group $(1.3 \% \pm 2.0 \%)$ (Fig. $2 \mathrm{C})(P>0.05)$.

The arrowhead right showed no development at all ages (\% changes: U-16, $1.0 \% \pm 1.7 \%$; U-17, $-1.5 \% \pm 4.1 \%$; U-18, $-0.7 \% \pm$ 2.1\%) (Fig. 3A) $(P>0.05)$. Significant differences were found in the arrowhead left (U-16, $1.5 \% \pm 1.6 \%$; U-18, $1.2 \% \pm 1.4 \% ; P<$ $0.05)$ after training; however, no difference was observed in U-17
$(-0.4 \% \pm 1.6 \% ; P>0.05)$ (Fig. 3B).

Coordination was enhanced further in U-16 (6.7\% $\pm 8.9 \%)$ and U-17 (5.5\% $\pm 6.9 \%)(P<0.05)$ compared with that in U-18 $(3.7 \% \pm$ 6.0\%) (Fig. 4) $(P>0.05)$.

The fatigue index of repeated sprints (U-16, 13.7\% $\pm 56.8 \%$; $\mathrm{U}-17,16.4 \% \pm 32.0 \%$; U-18, $-34.8 \% \pm 64.6 \%)$ and total time 

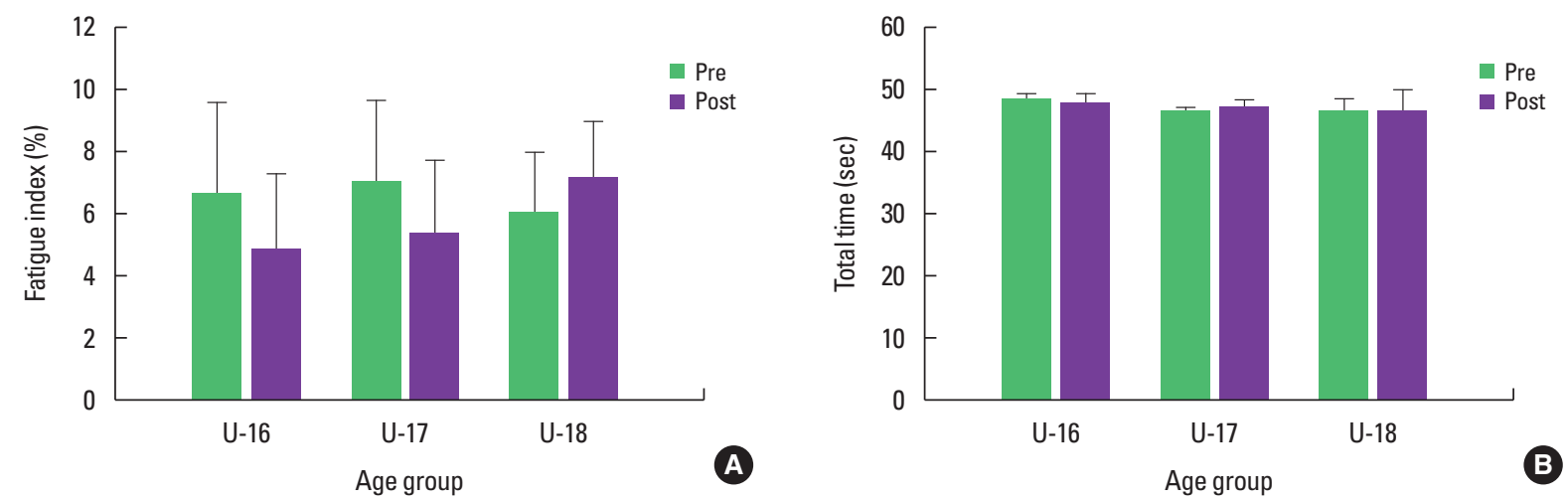

Fig. 5. Repeated sprints (A, B) in the age groups before and after 8-week preseason training ( $n=10$, mean \pm standard deviation).

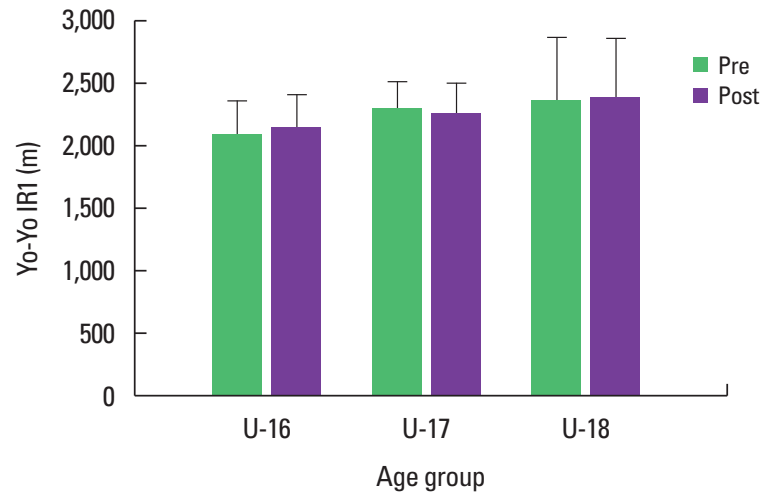

Fig. 6. Yo-Yo intermittent recovery test level 1 (IR1) in the age groups before and after 8-week preseason training $(n=10$, mean \pm standard deviation).

(U-16, $0.5 \% \pm 2.1 \%$; U-17, $-2.2 \% \pm 3.7 \%$; U-18, $-1.3 \% \pm 6.1 \%$ ) were similar between pre- and posttraining (Fig. 5A, B) $(P>0.05)$.

Performance of Yo-Yo IR1 was not changed after training in all age groups (U-16, 3.7\% $\pm 7.9 \%$; U-17, $-0.96 \% \pm 6.3 \%$; U-18, $2.3 \% \pm 5.6 \%)$ (Fig. 6) $(P>0.05)$.

\section{DISCUSSION}

This study mainly found slight differences in the tendency to improve fitness level after the 8-week preseason training according to age groups. Jump and sprint $(30 \mathrm{~m})$ performance improved at all age groups after training, but sprint $(10 \mathrm{~m})$, agility (arrowhead head right), repeated sprint, and Yo-Yo IR1 performance did not differ statistically between pre- and posttraining. Interestingly, the extent of development in agility (arrowhead head left) and coordination differed according to age groups.

In this study, jump performance developed in all ages after the training period. This result is consistent with that in a previous study that 8-week football-specific training improves the power of young players (Jovanovic et al., 2011). Power improvements in young football players are closely related to strength development. The increase in the muscle volume occurs during adolescence because of an increase in growth hormone levels (Ramos et al., 1998). While the increase in muscle mass is directly linked with the development of muscle strength, appropriate training methods must be applied to maximize development of muscle strength (Kawamori and Haff, 2004). In adolescence, when body growth is accelerated and muscle mass increases, the application of incorrect training methods can lead to serious injuries such as muscle and ligament rupture (Watson et al., 2019). Unfortunately, we did not measure the amount of increase in muscle volume among players, but it is suggested that 8 weeks of proper training improve jump performance through the development of muscle strength without serious injury in any age groups.

Improving strength-power through training affects record of sprints (Loturco et al., 2017). Indeed, the 30-m sprint performance in this study improved in all age groups after training. Similarly, the 20-m sprint performance was significantly enhanced in U-16 and U-18 and a tendency for improvement was shown in U-17 $(P=0.07)$. These findings support previous research findings that 6 weeks of preseason training improve the sprint ability of young football players (Asadi et al., 2018). However, in the present study, no statistical difference was found in the 10 -m sprint performance in all age groups. Unlike the $20-\mathrm{m}$ and $30-\mathrm{m}$ sprint, the absence of 10-m sprint performance development can be due to the training contents. The $10-\mathrm{m}$ sprint session during more than $30-\mathrm{m}$ sprinting was done during the acceleration phase of increasing the speed to reach the maximum speed. To increase the acceleration speed, which requires explosive power, muscle training is necessary to maximize muscle power (Morin and Samozino, 2016; Pavei et 
al., 2019). However, the 8 -week training in this study did not include explosive strength development, but consisted of training to improve various physical fitness levels and develop player's individual football skills and team tactics. Therefore, the intensity and volume of exercise in such training is somewhat insufficient to cause improvement in the 10-m sprint performance and development of explosive muscle strength.

Interestingly, in case of agility, arrowhead right performance did not differ between pre- and posttraining in all age groups, but arrowhead left performance improved in U-16 and U-18 through the training. This difference between the right and left directions of agility may be related to the player's body balance and/or dominant/nondominant leg. Football players' balance performance differs according to the playing position, and it is better in the nondominant leg than in the dominant leg (Jadczak et al., 2019). In this study, the players were right-leg dominant, and it was thought that the players were familiar with the right turning because the left leg supported the body weight when turning to the right direction. In addition, the 6-week training showed significantly an increase in balance performance in football players (Manolopoulos et al., 2016). Therefore, only the left direction might be developed through the training. In addition, in U-17, the training was not developed in both directions, unlike in the other two age groups. The number of players who used both feet freely was higher in U-17 than in other age groups (U-16 at 4, U-17 at 7, U-18 at 5). While the directional agility results are considered associated with the dominant leg, the association could not be analyzed in this study because of the limited sample size, which is a limitation of this study. Therefore, the relationship between directional turning speed and accuracy and whether the dominant leg affects the performance of football players should be analyzed in a future study.

Coordination is the ability to organize and control motor apparatus to achieve task goals, which is deeply related to skill performance (Santos et al., 2018). A football-specific test method with dribbling technique is mainly used to measure motor coordination of football players (Rommers et al., 2019). In this study, coordination was developed by training in U-16 and U-17, but no change was found in U-18. These results support those of previous study that the degree of neuromuscular system development is associated with age and the improvements in motor coordination can be influenced by the full maturity of the nervous system and enhanced neuromuscular efficiency in adolescence (Casamento-Moran et al., 2018; Portas et al., 2016). In addition, the coordination ability of football players did not decrease by detraining, unlike other fitness factors such as endurance and speed endurance, which decrease even with a short detraining period (Joo, 2016, 2018). Taken together, there may be an optimal period of time to maximize the improvement of coordination among football players, and while the degree of coordination development decreases after this period, it is not significantly reduced by detraining. In other words, the coordination that developed through training during adolescence remains at the same level regardless of increasing ages and detraining. Since this study was conducted for players aged 16-18 years, it was not possible to analyze the degree of coordination development before age 16 years. Therefore, to analyze the optimal development period and developmental characteristics of each age for coordination, further studies are needed for elite football players aged $<16$ years.

One of the characteristics of modern football is that the speed of the game, such as during passing, switching defending from attack, and attacking from defense, has been significantly faster. Given this change in game speed, the speed endurance of players, which demands a quick recovery after a sprint, has become more important among the physical fitness components. In this study, repeated sprint did not improve with training in all age groups. The results are inconsistent with those in previous study that general preseason football training reduces repeated sprint total time (Tønnessen et al., 2011). The difference in the results of these studies can be caused by the timing of measurement during preseason. While the pretest was conducted 2 weeks after the preseason training in this study, previous studies started the experiment after starting the preseason training, when the players' fitness level reduced through the off-season break period, to analyze changes in physical fitness through training. Therefore, the ability to repeat sprint can be possibly improved in the early stage of preseason training for 2 weeks, and the exercise intensity and volume of the subsequent 8-week training are insufficient to cause further increase in repeated sprints. Indeed, Joo (2018) reported that short term of training immediately after preseason improves repeated sprint ability.

Similar to the repeated sprint, no difference in the Yo-Yo IR1 performance was found between pre- and posttraining in all age groups. As mentioned earlier, these results would have been achieved by starting the experiment after the early stage of preseason training which induced an increase in the endurance of players. In general, preseason training for young football players is first started by endurance exercise according to the periodization theory (Favero and White, 2018). In a previous study, Papadakis et al. (2020) found that 9 weeks of preseason training improved the endurance of football players. Considering the results of these studies, the 
endurance of young football players improved by training in the early stages of the preseason, and the degree of increase through training during the subsequent training period is not large. However, intensity and training volumes higher than the player's fitness level can cause serious injury in the early training period during the preseason, so it is necessary to organize a training program in accordance with the periodization theory to improve the endurance of player without injuries.

This study was conducted to analyze differences in fitness improvement through an 8-week preseason training of young football players according to age groups. The 8-week training improved jump and sprint $(30 \mathrm{~m})$ performance in all age groups, but performance in sprint $(10 \mathrm{~m})$, agility (arrowhead right), repeated sprints, and Yo-Yo IR1 did not change after training. Differences in the amount of development were observed in agility (arrowhead left), speed $(20 \mathrm{~m})$, and coordination among age groups. While jump, sprint, repeated sprint, and Yo-Yo IR1 performances were similarly improved after the training period in all age groups, and coordination was improved mainly in the young age groups (U-16, U-17) compared with the older age group (U-18). Therefore, these results can suggest the importance of systematic and scientific training methods to improve the fitness levels of young football players in the preseason training period. Moreover, training to improve coordination in young football players is effective at younger ages.

\section{CONFLICT OF INTEREST}

No potential conflict of interest relevant to this article was reported.

\section{REFERENCES}

Abrantes C, Macas V, Sampaio J. Variation in football players' sprint test performance across different ages and levels of competition. J Sports Sci Med 2004;3:44-49.

Asadi A, Ramirez-Campillo R, Arazi H, Sáez de Villarreal E. The effects of maturation on jumping ability and sprint adaptations to plyometric training in youth soccer players. J Sports Sci 2018;36:2405-2411.

Bangsbo J, Iaia FM, Krustrup P. The Yo-Yo intermittent recovery test: a useful tool for evaluation of physical performance in intermittent sports. Sports Med 2008;38:37-51.

Bell W. Body size and shape: a longitudinal investigation of active and sedentary boys during adolescence. J Sports Sci 1993;11:127-138.

Buchheit M, Racinais S, Bilsborough JC, Bourdon PC, Voss SC, Hocking J,
Cordy J, Mendez-Villanueva A, Coutts AJ. Monitoring fitness, fatigue and running performance during a pre-season training camp in elite football players. J Sci Med Sport 2013;16:550-555.

Burris K, Liu S, Appelbaum L. Visual-motor expertise in athletes: Insights from semiparametric modelling of 2317 athletes tested on the Nike SPARQ Sensory Station. J Sports Sci 2020;38:320-329.

Casamento-Moran A, Fleeman R, Chen YT, Chen YT, Kwon M, Fox EJ, Yacoubi B, Christou EA. Neuromuscular variability and spatial accuracy in children and older adults. J Electromyogr Kinesiol 2018;41:27-33.

Favero TG, White J. Periodization in college soccer. Strength Cond J 2018; 40:33-44

Impellizzeri FM, Marcora SM, Castagna C, Reilly T, Sassi A, Iaia FM, Rampinini E. Physiological and performance effects of generic versus specific aerobic training in soccer players. Int J Sports Med 2006;27:483-492.

Jadczak Ł, Grygorowicz M, Wieczorek A, Śliwowski R. Analysis of static balance performance and dynamic postural priority according to playing position in elite soccer players. Gait Posture 2019;74:148-153.

Jeong TS, Reilly T, Morton J, Bae SW, Drust B. Quantification of the physiological loading of one week of "pre-season" and one week of "inseason" training in professional soccer players. J Sports Sci 2011;29: 1161-1166.

Joo $\mathrm{CH}$. The effects of short term detraining and retraining on physical fitness in elite soccer players. PLoS One 2018;13:e0196212.

Joo $\mathrm{CH}$. The effects of short-term detraining on exercise performance in soccer players. J Exerc Rehabil 2016;12:54-59.

Jovanovic M, Sporis G, Omrcen D, Fiorentini F. Effects of speed, agility, quickness training method on power performance in elite soccer players. J Strength Cond Res 2011;25:1285-1292.

Kawamori N, Haff GG. The optimal training load for the development of muscular power. J Strength Cond Res 2004;18:675-684.

Loturco I, Kobal R, Kitamura K, Cal Abad CC, Faust B, Almeida L, Pereira LA. Mixed training methods: effects of combining resisted sprints or plyometrics with optimum power loads on sprint and agility performance in professional soccer players. Front Physiol 2017;12:1034.

Manolopoulos K, Gissis I, Galazoulas C, Manolopoulos E, Patikas D, Gollhofer A, Kotzamanidis C. Effect of combined sensorimotor-resistance training on strength, balance, and jumping performance of soccer players. J Strength Cond Res 2016;30:53-59.

Mara JK, Thompson KG, Pumpa KL, Ball NB. Periodization and physical performance in elite female soccer players. Int J Sports Physiol Perform 2015;10:664-669.

McMillan K, Helgerud J, Macdonald R, Hoff J. Physiological adaptations to soccer specific endurance training in professional youth soccer players. Br J Sports Med 2005;39:273-277.

Morin JB, Samozino P. Interpreting power-force-velocity profiles for indi- 
vidualized and specific training. Int J Sports Physiol Perform 2016; 11:267-272.

Noon MR, James RS, Clarke ND, Akubat I, Thake CD. Perceptions of well-being and physical performance in English elite youth footballers across a season. J Sports Sci 2015;33:2106-2115.

Papadakis L, Tymvios C, Patras K. The relationship between training load and fitness indices over a pre-season in professional soccer players. J Sports Med Phys Fitness 2020;60:329-337.

Pavei G, Zamparo P, Fujii N, Otsu T, Numazu N, Minetti AE, Monte A. Comprehensive mechanical power analysis in sprint running acceleration. Scand J Med Sci Sports 2019;29:1892-1900.

Philippaerts RM, Vaeyens R, Janssens M, Van Renterghem B, Matthys D, Craen R, Bourgois J, Vrijens J, Beunen G, Malina RM. The relationship between peak height velocity and physical performance in youth soccer players. J Sports Sci 2006;24:221-230.

Portas MD, Parkin G, Roberts J, Batterham AM. Maturational effect on functional movement screenTM score in adolescent soccer players. J Sci Med Sport 2016;19:854-858.

Ramos E, Frontera WR, Llopart A, Feliciano D. Muscle strength and hor- monal levels in adolescents: gender related differences. Int J Sports Med 1998;19:526-531.

Rommers N, Mostaert M, Goossens L, Vaeyens R, Witvrouw E, Lenoir M, D'Hondt E. Age and maturity related differences in motor coordination among male elite youth soccer players. J Sports Sci 2019;37:196-203.

Santos R, Duarte R, Davids K, Teoldo I. Interpersonal coordination in soccer: interpreting literature to enhance the representativeness of task design, from dyads to teams. Front Psychol 2018;11:2550.

Thomassen M, Christensen PM, Gunnarsson TP, Nybo L, Bangsbo J. Effect of 2-wk intensified training and inactivity on muscle $\mathrm{Na}^{+}-\mathrm{K}^{+}$ pump expression, phospholemman (FXYD1) phosphorylation, and performance in soccer players. J Appl Physiol 2010;108:898-905.

Tønnessen E, Shalfawi SA, Haugen T, Enoksen E. The effect of 40-m repeated sprint training on maximum sprinting speed, repeated sprint speed endurance, vertical jump, and aerobic capacity in young elite male soccer players. J Strength Cond Res 2011;25:2364-2370.

Watson A, Mjaanes JM, Council on sports medicine and fitness. Soccer injuries in children and adolescents. Pediatrics 2019;144:e20192759. 